\title{
¿Qué queda de la teología de la liberación?*
}

\section{José Ignacio González Faus, Cristianismo y Justicia, Barcelona}

\section{Estado de la cuestión}

Esa pregunta se viene formulando desde hace tiempo con tonos algo triunfales, como si la duda significase que ya no queda nada y que fue una moda pasajera. Por eso, hay que comenzar respondiendo tajantemente: queda toda ella.

Pero ello no impide reconocer que la teología de la liberación (TL) puede estar atravesando una crisis importante, como una pubertad que parece desprenderse de muchos elementos de la vida anterior para recuperarlos después transformados en la madurez, si es que se ha sabido afrontar la crisis de la pubertad.

Valga o no valga el ejemplo anterior, aceptemos como punto de partida que la TL está en crisis. Pero no lo está porque "era marxista y el marxismo ha pasado". Ni tampoco por la caída de los regímenes del Este en el 89, sino más bien por la ofensiva neoliberal, con su "pensamiento único", y por la cultura individualista difundida por la economía neoliberal. Es, pues, una crisis externa no debida a ella misma, sino a ataques exteriores como los que reclamaba el documento de "Santa Fe" pedido por Reagan.

No obstante, a la pregunta que intitula este artículo, le sigue valiendo la vieja respuesta: quedan Dios y los pobres. Y a esa respuesta aún le añadiría yo un tercer remanente que está implícito en los dos citados: queda la historia. Últimamente he insistido en que la visión de Dios en la historia aparece como el aporte específico del cristianismo, cuando lo comparamos con otras experiencias de Dios: en la intimidad propia (Oriente asiático) y en la naturaleza (religiones amerindias con la Pachamama y demás). El cristianismo, por supuesto, no negará

* Charla impartida en noviembre de 2014 con los profesores del Departamento de Teología de la UCA, en San Salvador. 
ninguna de esas dos maneras de ver, pero les añade la presencia de Dios en la historia, que funge además como criterio de validación de las otras dos.

\section{Examen de conciencia}

Dicho lo anterior, hay que recordar que en los tiempos de crisis no conviene buscar las causas solo fuera de nosotros. Para superar la crisis es más útil buscar los errores propios y preguntarse qué es lo que hemos hecho mal. Y aquí conviene destacar al menos dos errores que me parecen innegables en la TL.

2.1. El primero fue la expectativa inminente de un cambio histórico positivo y cercano. La liberación se convertía así en un acontecimiento histórico más que una dimensión teológica. Y aquí sí creo que hubo un influjo muy negativo del marxismo y de su seguridad en la llegada de un paraíso ya al alcance de nuestras expectativas. Aquí y no en las mil sandeces de que se acusó a una TL supuestamente marxista (olvido de Dios, economicismo, materialismo, colectivismo...). Acusaciones todas que solo brotaban de una ignorancia no reconocida.

De hecho, L. Boff ya intuyó algo de esta insuficiencia cuando habló, ya en los primeros años, de teología de la liberación " $y$ del cautiverio". Pero esta segunda dimensión quedó olvidada, quizá por presiones ambientales de aquella hora histórica ${ }^{1}$.

2.2. El segundo fue el olvido de los mil problemas personales del ser humano y en concreto del hombre latinoamericano. No es que se los negara. Se los daba simplemente por supuestos, pero sin afrontarlos, esperando quizás que el cambio social inminente ayudaría a resolverlos. La atención a los problemas estructurales llevaba a olvidarse de mil aspectos de la liberación personal: el alcoholismo, por ejemplo; o los mil problemas afectivos, psicológicos, machistas, de abandono de la mujer. Este olvido dejó el campo abierto a las mil sectas norteamericanas que se han dedicado más a él, con la clara intención de no abordar los problemas estructurales, pero también con amplias posibilidades económicas y de cercanía del pastor (frente a la ausencia del cura, consecuencia de la ley positiva del celibato ministerial), que han ayudado a muchos individuos a liberarse de problemas personales verdaderos y agudos.

Dicho esto, será bueno también poner de relieve algunos logros de la TL, aunque solo sea para desmentir las mil acusaciones interesadas que proclaman su muerte con alegría no disimulada. Voy a prescindir de cómo haya podido fructi-

1. Me permito remitir sobre este punto a mi confrontación con la obra del gran J. P. Miranda (Marx y la Biblia), donde a la tesis del autor ("la fe cristiana consiste en creer que este mundo tiene remedio") contrapuse esta otra: la fe consiste en creer que tiene sentido luchar para que este mundo tenga remedio (ver el último capítulo de La teología de cada día, Salamanca, 1977²). 
ficar en América Latina, aunque parece innegable que la aparición de Gobiernos como los de Lula en Brasil, Correa en Ecuador o Evo Morales en Bolivia, y, en general, el auge actual de las izquierdas políticas en el subcontinente, tiene algún nexo importante con la TL.

2.3. Prescindiendo de lo anterior, la TL ha supuesto un despertar del cristianismo en los países del norte de Europa que ya dábamos por descristianizados. En este factor creo que ha influido también la presencia de muchos refugiados políticos de las pasadas dictaduras (por ejemplo, chilenos en Suecia). Pero a la vez, todos hemos conocido en Centroamérica pastores y pastoras de los países nórdicos. Y yo guardo una carta de un pastor finlandés (Sapio Taionara, ya fallecido) que había leído un folleto mío en Nicaragua y me pedía permiso para traducirlo (sin que la editorial cobrara derechos de traducción porque "en Finlandia es ruinoso publicar un libro religioso"). Y añadía que el cristianismo que aparecía allí es el único que puede revitalizar la fe en su país.

2.4. No sé cómo habrá continuado este fenómeno, pero el hecho es que se dio. Como se ha dado también, y mucho más, en el continente asiático con la aparición de las teologías dalit en India y mitjung en Corea. Allí, además, ha implicado una seria persecución de cristianos en la India y una importante vinculación de la TL con todo el tema de las religiones de Oriente. En ese mismo sentido, y pasando ahora a África, he contado otras veces mi encuentro en Javier, en 2006, con una teóloga laica anglicana, de Sudáfrica, mujer venerable ya con nietos, y que me explicaba que ella, allá donde iba o la llamaban, solo ofrecía "liberation theology". Y si le decían que eso estaba "demodé", insistía más en el tema para demostrar que no estaba pasado de moda.

Dejando la anécdota, nos quedaría reconocer al menos que si la TL ha muerto, pues ha muerto dando vida. Esa vida es la que puede hacerla fecunda en otros lugares, en caso de que la América elegida fuese infiel a la llamada que la TL supuso. Eso es lo menos que podrían reconocer los que ya se apresuran a entonarle responsos.

2.5. Finalmente, quiero enumerar solo otra aportación de la TL que no comentaré porque aparecerá en la tercera parte. Pero que quiero destacar para que no pase desapercibida. La TL ha convertido a las ciencias sociales en mediaciones auxiliares de la reflexión teológica, igual que antes lo era la filosofía y sin eliminar por ello a esta.

\section{Tareas pendientes}

Ahora nos quedaría, en una tercera parte, pensar cuáles parecen ser las tareas actuales de una TL, más necesaria que nunca, pero afectada también por la crisis global que ha sacudido a nuestra economía y, desde ella, también a toda nuestra cultura. Creo que han de ser sobre todo tareas "de escuelas", porque quizá está pasando la época de los grandes maestros individuales. 


\subsection{De la liberación a la apocalíptica}

Hace años (en 1995), en un número dedicado por la revista Sal Terrae a la misma pregunta de esta reflexión, hablé de la necesidad de pasar de la liberación a la apocalíptica. Para entender esta tarea es necesario precisar qué es la apocalíptica, para comprender qué puede hacerse hoy en otro lenguaje (no críptico y sin números) y qué debe significar además una crítica más abierta que en este caso no será al imperio del César, sino al imperio del dinero y a la llamada pseudoteología del mercado.

Antes, permítaseme reproducir la introducción del artículo citado de Sal Terrae, porque resumía todo el número de la revista ${ }^{2}$ y vale de respuesta a la pregunta de este artículo. Decía así: (a) Queda el método. Un modo de pensar que intenta ser transformador y no (solo) justificador... Y que hace la teología desde "la irrupción del pobre" y desde el privilegio hermenéutico de los pobres, hasta poder parafrasear un conocido dicho antiguo: "Fuera de los pobres no hay salvación". (b) Queda Dios. Que no se reveló como "buena noticia para los intelectuales" (aunque esto pueda ser lo que se da por añadidura cuando se busca el Reino de Dios y su justicia), sino como misericordia para los que carecen de ella. (c) Quedan los pobres y la opción por ellos... Como inmenso clamor no escuchado (que provoca la experiencia del Espíritu y la comprensión de la teología como "intellectus amoris") y como sacramento de lo que es todo ser humano ante Dios: un pobre necesitado de Su ayuda. (d) Quedan los mártires. Los mártires "según Jesús" y no "según el derecho canónico". Porque ni siquiera pueden vindicar para sí el título de mártires, ya que no murieron por "odio a la fe", sino, muchas veces, a manos de aquellos que - como Caifás - decían defender a Dios.

Esta panorámica es la que nos lleva a la apocalíptica, como visión teológica de la historia en tiempos de "cautiverio". La apocalíptica es eso, no meramente una profecía de calamidades estrambóticas. La palabra Apocalipsis, como ya sabemos, significa revelación, no catástrofe. Si se habla de desastres no es como algo que ocurrirá fatalmente, sino como algo que puede ocurrir. Porque la historia humana tiene una doble dimensión de promesa y de amenaza entre las que debemos aprender a movernos.

Si nos fijamos un poco, la narración bíblica está marcada por esa línea. Del Éxodo, como camino de liberación hacia la tierra prometida, se pasa a la destrucción de Jerusalén. Según los Evangelios, el mismo Jesús comienza su andadura anunciando el Reinado de Dios y la termina con aquellos discursos apocalípticos que cierran su vida pública. Y el cristianismo naciente del Nuevo Testamento comienza con anuncios como el de que Cristo nos liberó para que vivamos en

2. Donde escribían Antonio González, P. Casaldáliga, G. Gutiérrez y J. Sobrino 
libertad y se cierra con el libro del Apocalipsis, en el que ahora me fijaré un poquito más.

El Apocalipsis (tan leído estos días en América Latina) está escrito en tiempos de dificultad, persecución y sensación de promesas no cumplidas. Una situación así lleva a dos cosas: la primera, a proclamar de mil maneras que Dios sigue siendo el Señor de la historia, lo cual es una garantía de esperanza, como se lee en las visiones de los capítulos 21 y 22 sobre la ciudad futura. Por eso, la segunda tarea es la de denuncia: denuncia a la Iglesia (en las 7 cartas de los primeros capítulos) y denuncia a la sociedad. Nosotros estamos hoy invitados a la misma tarea: solo que ya no hemos de hacer la denuncia en términos crípticos, propios de situaciones de clandestinidad, porque, al menos, hemos conquistado cierta libertad de expresión ${ }^{3}$. Y tampoco hemos de hacerla con simbolismos numéricos porque ya no somos pitagóricos. Pero fuera de estos dos condicionamientos, creo que hoy se nos impone una tarea seria de denuncia.

Denuncia ¿de qué? De la actual "Babilonia” del capital, que solo produce ricos cada vez más ricos a costa de pobres cada vez más pobres. O del imperio del "Kyrios money", que sustituye al antiguo Kyrios Kaisar de los romanos, y al que contraponemos nuestra única confesión: Kyrios Iesus. Creo que este es el momento de retomar lo antes dicho sobre la mediación de las ciencias sociales en la reflexión teológica. No es que nosotros hayamos de ser economistas. ¡Ojalá pudiéramos! Pero desde el quizás predecesor D. Schweickart (que presentó su Against Capitalism en El Salvador) hasta los Stieglitz, Krugman, Piketti, Giraud, o los españoles Vicenç Navarro y J. Torres López, hay una cantidad de nombres que nos pueden ser muy útiles, al menos para perder el miedo a los falsos dogmas neoliberales disfrazados de ecuaciones, como el lobo de Caperucita: porque no se trata de discutir sus cálculos, sino los presupuestos de esos cálculos. Últimamente vengo repitiendo que toda economía se apoya en una "metaeconomía": unos presupuestos antropológicos que, si no son correctos, invalidarán todos los cálculos siguientes, como se invalida una ecuación cuando las incógnitas no tienen el valor que deben tener.

$\mathrm{Y}$ el presupuesto desde el que reflexionan los economistas neoliberales es que los seres humanos son consumidores-racionales-y-libres. Pues bien, los tres rasgos son inexactos. Los hombres y las mujeres somos algo más que consumidores y no podemos tolerar que se nos reduzca a solo eso. Y además, en cuanto consumidores, no somos en absoluto ni racionales ni libres. La publicidad sabe eso mucho mejor que los teólogos del mercado. Y esas son "las siete trompetas" que debemos hacer resonar y "los siete sellos" del libro que nos toca abrir. Para

3. Aunque quizá debería añadir que no sabemos cuánto durará esto, si las reacciones norteamericanas ante los Vatikileaks siguen por donde están comenzando a ir. 
eso tenemos también "siete señales" ( $c f$. Ap 8,$6 ; 14)$, hasta que desaparezca "la Bestia" y aparezca "la nueva Jerusalén".

Hoy en día, además, esta denuncia se hace más urgente que antaño por la gravedad de la amenaza ecológica que quizá sea la más densa de todas las negras nubes que hay en nuestro cielo. Y creo que aquí no basta yuxtaponer la tierra y los pobres (como quizás insinuaba el famoso título de Leonardo Boff ${ }^{4}$ ), sino comprender que hay una relación de causa y efecto: la tierra llora como madre, por el mal trato que damos a los más pobres; ella hace suyo ese daño, y vengará el dolor que hemos ido causando a sus hijos.

Curiosamente, en estos momentos en que tan necesaria es una denuncia seria, radical y bien fundamentada, los sociólogos hablan de una apostasía de los intelectuales. No sé si la teología debería suplir ese silencio ominoso.

\subsection{Una dimensión de toda la teología}

En segundo lugar, y aún más importante, la TL ha de dejar de ser vista como un tratado más o como una disciplina más de la teología, para pasar a ser una orientación (o un "objeto formal") de todos los tratados de la teología. En este mismo sentido, el famoso decreto $4 .^{\circ}$ de la Congregación General 32 de los jesuitas, sobre fe y justicia, decía que la promoción de la justicia no puede ser un "asunto exclusivo de unos cuantos jesuitas", sino que es "una de las dimensiones constantes de todo apostolado". Pues bien, alguna vez he visto un programa bienintencionado de algún centro, donde se hablaba por ejemplo de cristología, trinidad, eclesiología, teología de la liberación... Pero no se trata de eso, sino de que la cristología sea una cristología de la liberación, la eclesiología una eclesiología de la liberación... Porque solo eso evitará que hagamos (como decía G. Gutiérrez) una teología "de los amigos de Job", la cual cree poder hablar de Dios, al margen (o en contra) del sufrimiento del inocente.

De un Cristo anunciador del Reino y crucificado, revelador del Dios anonadado, y redentor de la injusticia humana, brotará entonces un tratado de Dios que sea del Dios de los pobres (revelado como buena noticia para ellos y no para los filósofos, como escribió A. González, hablando precisamente de la Trinidad ${ }^{5}$ ), lo que nos llevará a una eclesiología que sea de "la Iglesia de los pobres", a una antropología teológica que recupere la imprescindible paridad entre individuo y comunidad en el ser humano, lo que llevaría al tema jesuánico de reunir a "las ovejas perdidas" de la casa de Israel, así como a la atención a lo estructural y las ciencias sociales, y al tema marcusiano de las falsas necesidades. La escatología incorporará la aportación definitiva de Josep Giménez cuando

4. Grito de la tierra, grito de los pobres.

5. Cf. A. González, Trinidad y liberación, UCA Editores, 1994, p. 59. 
unifica la "palabra última", que es palabra sobre lo Último y palabra desde los últimos. Y finalmente, tendremos una sacramentología de los pobres. Quizás este último es el tratado que menos se ha visto afectado por la TL, pero puede serlo también. Pensemos por ejemplo en un bautismo como "entrada en la Iglesia" de los pobres, que supone un abrigo para luchar no solo contra el propio "pecado original", sino contra todo el pecado social y estructural; o en una confirmación que reafirme esa pertenencia a la Iglesia de los pobres con la opción personal que ello comporta; en una eucaristía que recupere el valor de los gestos más allá de la mera materia desnuda: partir el pan y pasar la copa, como símbolos ancestrales de esa doble actitud de compartir la necesidad y comunicar la alegría, que es como el testamento de Jesús y en el cual el Resucitado se hace realmente presente en la comunidad celebrante ${ }^{6}$. Todo esto ayudaría a superar la crisis actual de los sacramentos, nacida de su impostación demasiado mágica.

Y una última alusión en la que ya no puedo entretenerme: se ha dicho con razón que la TL era una forma de teología espiritual (baste recordar la frase de Schillebeeckx a Gustavo: "Tu metodología es tu espiritualidad"). Pues bien, desde aquí, esa TL que acabo de describir podría entrar en el actual interés por la mística, dándole veracidad y evitando que la mística buscada sea una simple huida de la realidad, y procurando buscar esa mística "de ojos abiertos" reclamada por J. B. Metz. Y con la mística viene dado el interés por los "testigos", que son lo único que resulta convincente en este mundo postmoderno sin casi verdades absolutas. Ahí tenemos el interés y el respeto que siguen despertando en el Primer Mundo figuras como Ignacio Ellacuría y sus compañeros. Pues bien, terminaré proponiéndoos una tarea: acaba de aparecer en España un libro titulado Maestros y testigos, que recoge las charlas dadas en el colegio mayor Chaminade de Madrid, el curso pasado. Allí se presentan unas pocas figuras (Juan XXIII, Bonhoeffer, Etty Hillesum...) de la amplia gama de testigos con que está regado nuestro siglo XX. Creo que algo semejante debería hacerse hoy en el subcontinente latinoamericano. Algo se ha hecho ya con monseñor Romero. Pero creo que debería ampliarse, porque América Latina está sembrada de testigos y de mártires. Ahí tenéis el libro de la argentina Clara Temporelli (Amigas fuertes de Dios) sobre mujeres mártires en América Latina.

Pues ahí queda eso. Y que el Señor os ayude a poner manos a la obra.

6. En este mismo sentido quise titular mi breve esbozo de sacramentología como Símbolos de fraternidad (Cuadernos Cristianismo y Justicia, n. ${ }^{\circ}$ 138). 